\title{
Germinação in vitro de sementes de alcachofra
}

\author{
Cassieli F de Moraes'; Marilei Suzin²; Alexandre Augusto Nienow²; Magali F Grando²; Nilton Manto- \\ vani $^{3}$; Eunice O Calvete ${ }^{2}$; Beatriz Terezinha Donida ${ }^{4}$ \\ ${ }^{2}$ UPF-FAMV, C. Postal 611, 99001-070 Passo Fundo-RS; ${ }^{3}$ UFSM, Frederico Westphalen-RS; ${ }^{4}$ Cooperativa Tritícola de Erechim Ltda, \\ Erechim-RS; 'Mestre em Agronomia, UPF-FAMV; cassielifm@hotmail.com; suzin@upf.br; mantovani.nilton@gmail.com; beatriz@ \\ cotrel.com.br
}

\section{RESUMO}

A baixa taxa de multiplicação e alta de contaminação dos explantes são algumas das dificuldades na micropropagação da alcachofra. A germinação de sementes in vitro pode ser uma alternativa de obtenção de explantes sadios para estabelecimento de futuros cultivos in vitro. O trabalho desenvolvido no Laboratório de Biotecnologia Vegetal da UPF-FAMV teve por objetivo avaliar a germinação in vitro de sementes de alcachofra cv. Nobre, em três experimentos, testando concentrações de cloro ativo na assepsia das sementes; tratamentos do tegumento (mantido intacto, com cortes laterais ou eliminação); condições de luminosidade (claro ou escuro); e dois meios de cultura [meio MS, com concentração de sais reduzida à metade (M1) e meio MS completo(M2)]. Em ambos foram adicionados $30 \mathrm{~g} \mathrm{~L}^{-1} \mathrm{de}$ sacarose e $7 \mathrm{~g} \mathrm{~L}^{-1}$ de ágar, sendo o $\mathrm{pH}$ ajustado para 5,6 $\pm 0,1 \mathrm{com}$ $\mathrm{NaOH}$. Os cultivos foram realizados em câmara de crescimento. A obtenção de plântulas sadias de alcachofra em curto espaço de tempo (sete dias), para utilização como fonte de explantes é viável a partir da germinação in vitro de sementes sem o tegumento $(77,5 \%$ de germinação), utilizando os meios de cultura M1 ou M2 e câmara de crescimento desprovida de luz. Nestas condições, a assepsia das sementes pode ser realizada com álcool $70 \%$ por 30 min e posterior imersão em solução contendo $2 \%$ de cloro ativo por dez minutos, antes da remoção do tegumento.

Palavras-chave: [Cynara cardunculus L. subsp. scolymus (L.) Fiori], meio de cultura, explante, cultivo in vitro.

\begin{abstract}
In vitro artichoke seed germination

Low multiplication rates and high contamination in the explants are some of the difficulties in artichoke micropropagation. In vitro seed germination may be an alternative to obtain healthy explants for use in future in vitro cultivation. This project developed at the laboratory of Universidade de Passo Fundo was established to evaluate cv. 'Nobre' artichoke seeds in vitro germination. In three experiments, active chloride concentrations on seed aseptic technique; tegument treatment (kept intact, with side cuts and elimination); lighting conditions (light or dark); and two cultivation media [MS medium, with salts concentration reduced by half (M1) and MS medium, full strenger (M2)] have been tested. In both cases, $30 \mathrm{~g} \mathrm{~L}^{-1}$ sucrose and $7 \mathrm{~g} \mathrm{~L}^{-1}$ agar were added, with $\mathrm{pH}$ adjusted to 5.6 with $\mathrm{NaOH}$. Cultivation took place in a growth chamber. It is viable to obtain healthy artichoke plantlets in short time (seven days), to be used as a source of explants from in vitro seed germination without the tegument (77,5\% of germination), using the M1 or M2 culture medium and growth chamber without light. In these conditions, the asepsis of seeds can be done with alcohol $70 \%$ during 30 minutes and the subsequent immersion in solution of $2 \%$ of active chlorine during 10 minutes, before the removal of the tegument.
\end{abstract}

Keywords: [Cynara cardunculus L. subsp. scolymus (L.) Fiori], culture medium, explant, in vitro culture.

(Recebido para publicação em 27 de março de 2009; aceito em 1 de fevereiro de 2010) (Received on March 27, 2009; accepted on February 1, 2010)

\begin{abstract}
$\mathrm{A}_{\mathrm{L}}^{\mathrm{a}}$ alcachofra (Cynara cardunculus L. subsp. scolymus (L.) Fiori), pertencente à família Asteraceae (Robles, 2001), é uma planta herbácea típica da bacia do Mediterrâneo (Barba et al., 2004). As inflorescências (capítulos) são muito apreciadas para o consumo in natura ou industrializado (Narváez, 2002). A demanda como planta medicinal tem aumentado durante as últimas décadas devido à grande aceitação de suas folhas e inflorescências para o tratamento de várias doenças e enfermidades (Eich et al., 2005). A alcachofra também é utilizada como planta ornamental, em hortas e jardins, devido às belas inflorescências e às folhas grandes e brilhantes.
\end{abstract}

Em 1994, na região norte do Rio
Grande do Sul, a Cooperativa Tritícola de Erechim (Cotrel, 2005), em um convênio com a Itália, introduziu a cultura da alcachofra, criando um programa de produção entre seus associados, com a finalidade de industrializar o produto e oferecer fonte de renda alternativa para os pequenos produtores (Donida, 2004). A partir do material introduzido da Itália foram selecionados exemplares que apresentavam características adequadas para a indústria. Desta seleção surgiu a cultivar Nobre, que é hoje cultivada exclusivamente na Região do Alto Uruguai do RS, para fabricação de conservas. Esta cultivar possui como características o capítulo alongado, com brácteas compactas e de coloração interna branca, características exigidas pela indústria de conservas.

Alguns problemas entretanto têm impedido a maior expansão da cultura no RS, como por exemplo a produção de mudas para a distribuição aos produtores. A partir de sementes, os materiais oriundos da Itália apresentaram boa adaptação local, com elevada produtividade. No entanto, o grau de segregação se mostrou elevado, com a produção de capítulos que não serviam para a indústria de conservas, devido ao padrão desuniforme de coloração e tamanho, não atendendo às exigências do mercado consumidor. Outro entrave tem sido o baixo índice de pega das mudas, devido aos solos da região muito argilosos e à 
suscetibilidade da cultura à bactéria do gênero Erwinia, muito comum nos solos da região de cultivo.

A propagação da alcachofra por sementes apresenta algumas vantagens, tais como possibilidade da semeadura mecânica, reduzindo custos de mãode-obra, e rotação com outras espécies, para o controle de moléstias e nematóides (Basnizki \& Zohary, 1987). Outro aspecto importante é a prevenção de viroses, que não são transmitidas através da semente (Basnizki \& Zohary, 1987; Camargo, 1992). No entanto, as cultivares de alcachofra são altamente heterozigotas, uma vez que a cultura é alógama (polinização cruzada), segregando quando propagadas por semente, originando progênies com elevada variabilidade morfológica (Robles, 2001), inclusive plantas com espinhos, produtoras de capítulos não comestíveis, semelhantes ao cardo (Cynara cardunculus L.) (Camargo, 1992). Apesar disso, vem sendo observada uma tendência do melhoramento genético para o desenvolvimento de cultivares anuais, que se reproduzem por sementes, com certo grau de uniformidade e geração de poucos rebentos (Robles, 2001).

O processo de propagação vegetativa por rebentos é utilizado por acelerar o início da colheita e reproduzir com segurança as características da planta matriz (Robles, 2001). Entretanto, é necessário ter alguns cuidados ao adquirir as mudas, pois podem ocorrer problemas com a disseminação de pragas, bacterioses e fungos (Isechi et al., 1998).

A micropropagação é uma técnica alternativa de propagação assexuada, que apresenta a vantagem de reduzir a disseminação de doenças e a segregação genética. Estudando a micropropagação da alcachofra a partir de ápices vegetativos, Cadinu et al. (2003) obtiveram $50 \%$ de plantas isentas de vírus no meio MS.

O sucesso da micropropagação pode estar na dependência de fatores genéticos, fisiológicos ou ambientais, podendo ser encontrada grande variabilidade nas respostas in vitro, levando à necessidade de se definirem protocolos diferenciados (Grattapaglia \& Machado, 1998). Especificamente na micropropagação da alcachofra têm sido encontradas dificuldades como a baixa taxa de multiplicação in vitro e alta de contaminação dos explantes. Augustin et al. (2006) avaliaram a taxa de multiplicação de ápices caulinares da alcachofra cv. Nobre em três meios de cultura e o desenvolvimento das plântulas durante cinco subcultivos. Concluíram que a taxa de multiplicação é baixa, independente do meio de cultura, sendo a maior taxa obtida de 2,68 brotos por plântula.

Durante a micropropagação é comum ocorrerem perdas significativas devido à contaminação por microrganismos presentes na superfície dos explantes ou, endofíticos, principalmente fungos e bactérias. A ocorrência de contaminações é mais freqüente quando se realiza a micropropagação de espécies lenhosas, ou quando a assepsia é difícil de ser executada, devido às características do explante, ou por este estar localizado em regiões da planta matriz próximas do solo (Suzin, 2004), como no caso da alcachofra (Mauromicale, 1984).

A germinação de sementes de alcachofra in vitro pode ser uma alternativa para a obtenção de explantes livres de infestações para serem utilizados no processo de micropropagação.

O processo de germinação de sementes in vitro visando a produção de mudas tem sido utilizado em outras espécies, como, em aroeira (Myracrodruon urundeuva Fr. All.) (Andrade et al., 2000), em mangabeira (Hancornia speciosa Gomez) (Pinheiro et al., 2001), em orquídeas (Bach \& Castro, 2004; Castro \& Bach, 2007), em fisalis (Physalis peruviana L.) (Chaves et al., 2005), em jacarandá (Jacaranda ulei Bureau e K. Schum) (Noleto et al., 2003), em pessegueiro (Prunus persica) (Barbosa et al., 1985) e em bromélia (Vriesea simplex) (Bromeliaceae) (Castro et al., 2007).

O trabalho objetivou avaliar a germinação de sementes de alcachofra cv. Nobre em dois meios de cultura, submetidas a diferentes processos de assepsia, tratamentos do tegumento e influência da presença e ausência de luz.

\section{MATERIAL E MÉTODOS}

No período de outubro de 2006 a fevereiro de 2007 foram realizados três experimentos no Laboratório de Biotecnologia Vegetal da Faculdade de Agronomia e Medicina Veterinária (FAMV), da Universidade de Passo Fundo (UPF), em Passo Fundo-RS.

Selecionou-se sementes de alcachofra, cv. Nobre, uniformes e sem deformidades (com maior tamanho e melhor aparência). As mesmas foram tratadas com o fungicida Thiram 480 $\mathrm{TS}^{\circledR}$ (ingrediente ativo Tiram $280 \mathrm{~mL}$ i.a. por $100 \mathrm{~kg}$ de semente) e lavadas três vezes com água destilada e autoclavada para retirada do excesso de fungicida e impurezas mais grosseiras. Em câmara de fluxo laminar, utilizando pinças, placas de Petri e frascos de vidro previamente esterilizados, foi realizada a assepsia das sementes com álcool $70 \%$ por 30 minutos e hipoclorito de sódio com concentrações variando conforme o experimento, sendo em seguida lavadas três vezes com água destilada e autoclavada. Antes dos tratamentos no tegumento e da semeadura, as sementes foram mantidas imersas por 24 ou $48 \mathrm{~h}$, conforme o experimento, em água também destilada e autoclavada, num volume de 1 L para cada 100 sementes, em beakers fechados com papel alumínio e mantidos em câmara de fluxo laminar no escuro. Passado o período de imersão, as sementes foram lavadas por mais três vezes antes de serem submetidas aos respectivos tratamentos.

Para a semeadura foram utilizados frascos de vidro de $250 \mathrm{~mL}$, onde foi vertido cerca de $30 \mathrm{~mL}$ de meio de cultura $(2 \mathrm{~cm})$. Em cada frasco foram colocadas 6 sementes. Os meios de cultura utilizados para a semeadura foram: meio MS (Murashige \& Skoog, 1962) com concentração de sais reduzida à metade (M1); e meio MS completo (M2). Em ambos adicionou-se $30 \mathrm{~g} \mathrm{~L}^{-1}$ de sacarose e $7 \mathrm{~g} \mathrm{~L}^{-1}$ de ágar, sendo o $\mathrm{pH}$ ajustado para 5,6 $\pm 0,1 \mathrm{com} \mathrm{NaOH}$.

$\mathrm{O}$ cultivo in vitro das sementes foi realizado, em todos os experimentos, em câmara de crescimento com temperatura de $25 \pm 2^{\circ} \mathrm{C}$. Quando na presença de luz, o fotoperíodo mantido foi de 16 horas de luz e radiação de $36 \mu \mathrm{mol} \mathrm{m} \mathrm{m}^{-2} \mathrm{~s}^{-1}$.

Experimento 1 - foi testada a germinação das sementes de alcachofra com luz e no escuro, em dois meios de cultura (M1 e M2), comparando ainda, o efeito 
da realização ou não de um corte longitudinal em cada lateral do tegumento das sementes. A assepsia das sementes foi realizada com álcool $70 \%$ por $30 \mathrm{~min}$ + hipoclorito de sódio $(8,3 \%$ de cloro ativo com $\mathrm{pH}$ ajustado para 6,0) por dez minutos. Após a imersão em água por 24 horas, conforme descrito anteriormente, foram realizados os cortes laterais do tegumento.

Os frascos com as sementes foram mantidos em câmara de crescimento, sendo parte deles mantidos sob luz (no claro) e outra no escuro. O delineamento experimental foi inteiramente casualizado, com os tratamentos arranjados em parcelas subdivididas, com a presença/ausência de luz constituindo as parcelas principais e, nas subparcelas, sendo alocados os fatores meios de cultura $\mathrm{x}$ tratamento do tegumento, com cinco repetições e seis sementes por subparcela.

Após 30 dias da semeadura foram avaliadas as sementes com rompimento do tegumento $(\%)$, com emissão de cotilédones, com emissão da radícula e de sementes contaminadas. Por não apresentar variabilidade entre os tratamentos, os dados de emissão de cotilédones e de radícula não foram submetidos à análise estatística. As demais variáveis foram submetidas à análise de variância, e as diferenças entre médias comparadas pelo teste de Tukey a 5\% de significância. Para efeito de análise estatística os dados foram transformados em arco seno [raiz (x/100)]. O programa estatístico Estat (Unesp-Jaboticabal) foi utilizado na análise deste e dos demais experimentos.

Experimento 2 - as sementes também foram semeadas em dois meios de cultura (M1 e M2), com e sem corte lateral do tegumento e imersão em água por 24 horas antes do corte lateral e da semeadura. Porém, a assepsia das mesmas foi realizada com menor concentração de cloro ativo (álcool $70 \%$ por $30 \mathrm{~min}+$ hipoclorito de sódio 5,7\% de cloro ativo por dez minutos), uma vez que foi cogitada a hipótese de que altas concentrações de hipoclorito poderiam ter efeito tóxico sobre a germinação das sementes in vitro. Outro diferencial neste experimento foi que os frascos com as sementes em meio de cultura foram mantidos em câmara de crescimento apenas no escuro, em razão de que, no experimento 1 , foi observada menor oxidação dos cotilédones emitidos quando as sementes foram mantidas nessa condição.

O delineamento experimental foi inteiramente casualizado, com os tratamentos arranjados no esquema fatorial 2 x 2 (sem e com corte do tegumento $\mathrm{x}$ meios de cultura M1 e M2), com cinco repetições e seis sementes por parcela.

Foram realizadas cinco avaliações (5, 10, 15, 20 e 25 dias após a semeadura) da porcentagem de sementes com rompimento do tegumento e de sementes contaminadas. Os dados foram submetidos, em cada época avaliada, à análise de variância. Para a comparação entre as datas de avaliação, em cada tratamento, foi aplicada a análise de variância da regressão.

Experimento 3 - foi estudado o efeito da remoção total do tegumento, comparado com sementes mantidas intactas, em dois meios de cultura (M1 e M2). Com a remoção do tegumento foi possível visualizar e selecionar apenas as sementes sadias. A assepsia das sementes foi realizada antes da remoção do tegumento, em câmara de fluxo laminar, e constituiu-se da imersão das mesmas em álcool $70 \%$ por 30 min e, posteriormente, em hipoclorito de sódio ( $2 \%$ de cloro ativo) por dez minutos. O tempo de imersão das sementes em água antes da semeadura foi ampliado de 24 para $48 \mathrm{~h}$ para facilitar a retirada do tegumento. As sementes em meio de cultura foram mantidas em câmara de crescimento no escuro.

$\mathrm{O}$ delineamento experimental foi inteiramente casualizado, com os tratamentos arranjados no esquema fatorial $2 \times 2$ (sem e com a retirada do tegumento x meios de cultura M1 e M2), com cinco repetições e 24 sementes por parcela (quatro frascos com seis sementes). Os dados de germinação (\%) (emissão de cotilédones + radícula) e de contaminação, aos sete dias após a semeadura, foram submetidos à análise de variância.

\section{RESULTADOS E DICUSSÃO}

Experimento 1 - o meio de cultura e a luz não influenciaram os resultados. As sementes com rompimento do tegumento foram beneficiada, ainda que de forma reduzida $(12,5 \%)$, apenas pela realização de cortes na lateral do tegumento. Já as sementes intactas (sem cortes) apresentaram apenas 2,5\% de rompimento do tegumento. Esses resultados reforçam a teoria de que a presença do tegumento realmente constitui uma barreira física à germinação das sementes. Resultados semelhantes foram observados por Custódio et al. (2002) com urucum (Bixa ollerana L.), em que a estratificação das sementes cortadas na porção distal do tegumento se mostrou eficaz para superar a dormência.

Franco \& Ferreira (2002) também observaram, na germinação de sementes de caixeta [Didymopanax morototoni (Aubl.) Dcne. et Planch], que a escarificação mecânica do tegumento com lixa ou a realização de cortes no mesmo favoreceu a germinação, provavelmente por tornar o tegumento mais fino, reduzindo o impedimento físico e permitindo a passagem de água até o embrião.

Também foi observado que, do total de 240 sementes analisadas, apenas 2,1\% apresentaram emissão dos cotilédones e nenhuma apresentou emissão de radícula.

Embora vários autores relatem a influência da luz na germinação de sementes, no presente trabalho este efeito não foi verificado. Conforme Bewley \& Black (1994), as sementes de muitas espécies são afetadas pela exposição à luz branca por alguns minutos ou segundos, enquanto que outras requerem iluminação intermitente. Também existem os efeitos fotoperiódicos, em que algumas espécies requerem exposições a dias longos e outras a dias curtos. Convém destacar, que o requerimento de luz freqüentemente depende da temperatura. A alface por exemplo, geralmente apresenta dormência no escuro somente acima de $23^{\circ} \mathrm{C}$.

Miccolis et al., apud Donida (2004), mencionam que a redução da germinação e morte de plântulas de alcachofra podem ocorrer devido ao baixo vigor das sementes, o que estaria associado a altas temperaturas, além dos danos mecânicos e imaturidade das sementes. A precipitação pluviométrica pode interferir 
Tabela 1. Rompimento do tegumento de sementes de alcachofra cv. Nobre em dois meios de cultura, com e sem o corte lateral (disruption of artichoke cv. Nobre seed tegument in two culture media with and without lateral cut). Passo Fundo, UPF, 2006.

\begin{tabular}{lccccc}
\hline \multirow{2}{*}{ Tratamentos } & $\mathbf{5}$ Rompimento do tegumento (\%) \\
\cline { 2 - 6 } & $\mathbf{5}$ & $\mathbf{1 0}$ & $\mathbf{1 5}$ & $\mathbf{2 0}$ & $\mathbf{2 5}$ \\
\cline { 2 - 6 } & $16,7^{\mathrm{ns}}$ & $23,3^{\mathrm{ns}}$ & $25,0^{\mathrm{ns}}$ & $31,7^{\mathrm{ns}}$ & $31,7^{\mathrm{ns}}$ \\
\hline M1 - 1/2 MS & 11,7 & 10,0 & 11,7 & 16,7 & 18,3 \\
\hline M2 - MS completo & $15,0^{\mathrm{ns}}$ & $20,0^{\mathrm{ns}}$ & $23,4^{\mathrm{ns}}$ & $33,3^{\mathrm{ns}}$ & $33,4^{\mathrm{ns}}$ \\
\hline Tegumento com cortes & 13,4 & 13,4 & 13,4 & 15,0 & 16,7 \\
Tegumento intacto & 14,2 & 16,7 & 18,4 & 24,2 & 25,0 \\
\hline Média & 101,8 & 103,6 & 96,4 & 88,6 & 84,4 \\
\hline CV (\%) & &
\end{tabular}

$\mathrm{Ns}=$ não significativo pelo teste $\mathrm{F}$ a $5 \%$ de significância (not significant for the test $\mathrm{F}$ \%\% of significance).

diretamente na qualidade da semente e na porcentagem de germinação. Assim, não se pode descartar certo comprometimento do vigor das sementes utilizadas no experimento, uma vez provenientes de lavouras de produção, expostas a fatores adversos, como alta temperatura e excesso de chuvas.

Quanto às sementes contaminadas, apenas o fator luminosidade afetou esta variável, com maior contaminação no escuro (média de 35\%) e menor com $\operatorname{luz}(7,5 \%)$.

Aluz, quando em grande intensidade, pode ser nociva para os microrganismos, devido à ocorrência da fotoxidação do oxigênio. Nesta reação, pigmentos como clorofila, citocromos e flavinas podem absorver energia luminosa e atuar como fotosensibilizadores excitados, os quais transferem energia para o $\mathrm{O}_{2}$, originando moléculas de ${ }^{1} \mathrm{O}_{2}$, que são agentes oxidantes que causam a destruição da célula (fotoxidação) e, em conseqüência, a morte dos microrganismos presentes na mesma (Moniz, 2006).

Compostos como o peróxido de hidrogênio $\left(\mathrm{H}_{2} \mathrm{O}_{2}\right)$, o superóxido de oxigênio $\left(\mathrm{O}_{2}^{-}\right)$e radicais de hidroxila livres $\left(\mathrm{OH}^{-}\right)$podem ser produzidos em função de processos oxidativos (mediante a ativação de elétrons), injúrias no tecido vegetal e presença de fatores abióticos (UV, altas temperaturas, poluentes, estresse osmótico e mecânico). Estes podem ter diversas funções na defesa dos tecidos ou plantas a patógenos. Podem agir como agente antifúngico e antimicrobiano (efeito tóxico direto); servir como sinalizadores para a ativação de genes de defesa; e promover a morte celular no tecido infectado (Cursino-Santos et al., 2003; Resende et al., 2003).

Embora a permanência das sementes no escuro tenha favorecido o aparecimento de contaminações, o aspecto visual das que apresentaram rompimento

Tabela 2. Contaminação de sementes de alcachofra cv. Nobre em dois meios de cultura, com e sem o corte lateral do tegumento (contamination of artichoke cv. Nobre seeds in two culture media, with and without lateral cut of tegument). Passo Fundo, UPF, 2006.

\begin{tabular}{|c|c|c|c|c|c|}
\hline \multirow{3}{*}{ Tratamentos } & \multicolumn{5}{|c|}{ Sementes contaminadas $(\%)$} \\
\hline & \multicolumn{5}{|c|}{ Dias após a semeadura } \\
\hline & 5 & 10 & 15 & 20 & 25 \\
\hline M1 - 1/2 MS & $5,0^{\mathrm{ns}}$ & $28,3^{\text {ns }}$ & $55,0^{\text {ns }}$ & $65,5^{\text {ns }}$ & $70,0^{\text {ns }}$ \\
\hline M2 - MS completo & 10,0 & 35,0 & 60,0 & 80,0 & 90,0 \\
\hline Tegumento com cortes & $5,0^{\mathrm{ns}}$ & $31,7^{\mathrm{ns}}$ & $63,3^{\text {ns }}$ & $80,0^{\text {ns }}$ & $80,0^{\text {ns }}$ \\
\hline Tegumento intacto & 10,0 & 31,7 & 51,7 & 65,0 & 80,0 \\
\hline Média & 7,5 & 31,7 & 57,5 & 72,5 & 80,0 \\
\hline CV (\%) & 153,0 & 80,3 & 63,5 & 53,0 & 52,3 \\
\hline
\end{tabular}

$\mathrm{ns}=$ não significativo pelo teste $\mathrm{F}$ a $5 \%$ de significância (not significant for the test $\mathrm{F} 5 \%$ of significance).

de tegumento e emissão de cotilédones foi satisfatório, ou seja, não apresentavam oxidação. Assim, adotou-se para os demais experimentos a manutenção das sementes no escuro.

Experimento 2 - com a concentração de cloro ativo reduzido para $5,7 \%$ e semeadura no escuro, não houve efeito, em nenhuma das épocas avaliadas (no decorrer de 25 dias da semeadura), dos dois meios de cultura e dos tratamentos de corte no tegumento (com e sem corte) sobre o rompimento do tegumento e a contaminação das sementes (Tabela 1).

A porcentagem de sementes com rompimento do tegumento não foi satisfatória, variando de $14,2 \%$, aos cinco dias após a semeadura, a 25,0\%, aos 25 dias. Embora diferenças estatísticas não tenham sido verificadas, foi possível observar uma tendência de melhores resultados no meio M1 e com cortes laterais das sementes. No entanto, a germinação (com emissão de cotilédones + radícula) não foi observada em nenhum dos tratamentos.

A análise de regressão demonstrou que, ao longo do período de 25 dias da semeadura, houve aumento linear significativo da porcentagem de tegumentos rompidos quando as sementes tiveram os mesmos submetidos aos cortes e semeadas no meio M2 (Figura 1). Também no meio M1 houve uma tendência de acréscimo de tegumentos rompidos, contudo a análise de regressão não se mostrou significativa.

Como foi salientado anteriormente, o baixo índice de germinação das sementes de alcachofra pode estar associado ao tegumento muito duro, difícil de ser removido. A execução de cortes laterais no tegumento provavelmente permite que a água penetre e chegue ao embrião, possibilitando o início do processo germinativo. Contudo, uma vez que não houve a emissão da radícula e dos cotilédones, o processo não foi completo.

O índice de contaminação, aos 25 dias, foi bastante elevado (média de $80 \%$ ), não diferindo, em cada época avaliada, em função do meio de cultura e dos tratamentos de corte no tegumento (Tabela 2). Neste experimento, a contaminação das sementes foi maior do que no experimento 1 , possivelmente pela 


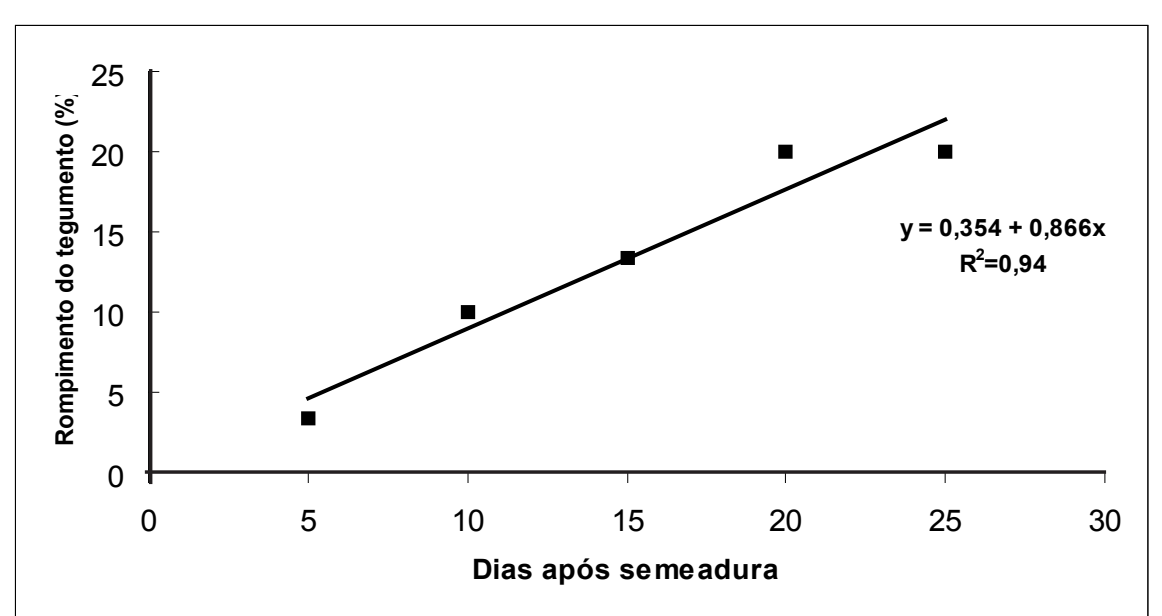

Figura 1. Rompimento do tegumento de sementes de alcachofra cv. Nobre no meio de cultura M2 (MS completo), com corte lateral do tegumento (disruption of artichoke cv. Nobre seed tegument in M2 culture media (complete MS), with lateral cut of tegument). Passo Fundo, UPF, 2006.

diminuição na concentração de cloro ativo na solução utilizada na assepsia das sementes.

De acordo com Hirata \& Mancini Filho (2002), apud Domini et al. (2005), o mecanismo de ação do cloro ativo não é bem conhecido, mas hipóteses consideram que pode haver uma combinação do cloro com proteínas da membrana celular dos microrganismos, causando alterações estruturais da membrana, ou interferindo no transporte de nutrientes através da mesma, formando compostos tóxicos e levando à inibição de enzimas essenciais. No entanto, fatores como $\mathrm{pH}$ (Bizzetto \& Homechin, 1999), concentração do agente esterilizante e tempo de exposição do explante ao mesmo são fatores que podem contribuir para o sucesso da desinfestação (Domini et al., 2005).

A análise de regressão demonstrou que houve, ao longo do período de 25 dias após a semeadura, para todas as combinações de tratamentos (meios de cultura $\mathrm{x}$ tratamento do tegumento), aumento linear significativo da porcentagem de contaminação (Figura 2).

A contaminação das sementes nos meios de cultura foi ocasionada pelo aparecimento de bactérias e fungos, provavelmente endógenos à semente. Segundo Donida (2004), o poder germinativo das sementes de alcachofra pode ser afetado pelos patógenos associados à mesma. Miccolis et al., apud Donida
(2004), obervaram a presença dos gêneros de fungos Rhizopus, Alternaria e Aspergillus associados à semente, no entanto, a melhoria da germinação foi verificada com o tratamento utilizando sulfato de 8-hydroxy quinona, tiram e captan.

Experimento 3 - Diante das dificuldades em obter germinação nos experimentos anteriores, neste experimento foi testada a remoção total do tegumento para verificar se este realmente se constituía numa barreira física à germinação. As sementes foram mantidas no escuro, em função da menor ocorrência de oxidação dos cotilédones.

Para minimizar o possível efeito residual tóxico do cloro ativo, foi reduzida a concentração do mesmo de 5,7 para $2 \%$ na assepsia das sementes. Já o tempo de imersão das sementes antes da semeadura em água foi ampliado de $24 \mathrm{~h}$ para $48 \mathrm{~h}$, para facilitar a remoção do tegumento.

Houve efeito significativo apenas do tratamento dado ao tegumento da semente sobre a porcentagem de germinação. A remoção total do tegumento possibilitou uma rápida e satisfatória germinação $(77,5 \%)$, apresentando as plântulas aos sete dias porte para a retirada de explantes (repicagem). As sementes com o tegumento mantido intacto não germinaram. O meio de cultura não revelou efeito significativo sobre a germinação das sementes. Verificou-se, portanto, que o tegumento da semente de alcachofra se constitui numa barreira física à germinação. Outro aspecto a considerar é que a remoção total do tegumento permitiu visualizar e selecionar as sementes mais sadias, o que pode ter favorecido a maior porcentagem de germinação nesse tratamento.

Os resultados são concordantes com Pinheiro et al. (2001) que, na germinação in vitro da mangabeira (Hancomia speciosa G.), em diferentes meios de cultura, observaram que as sementes

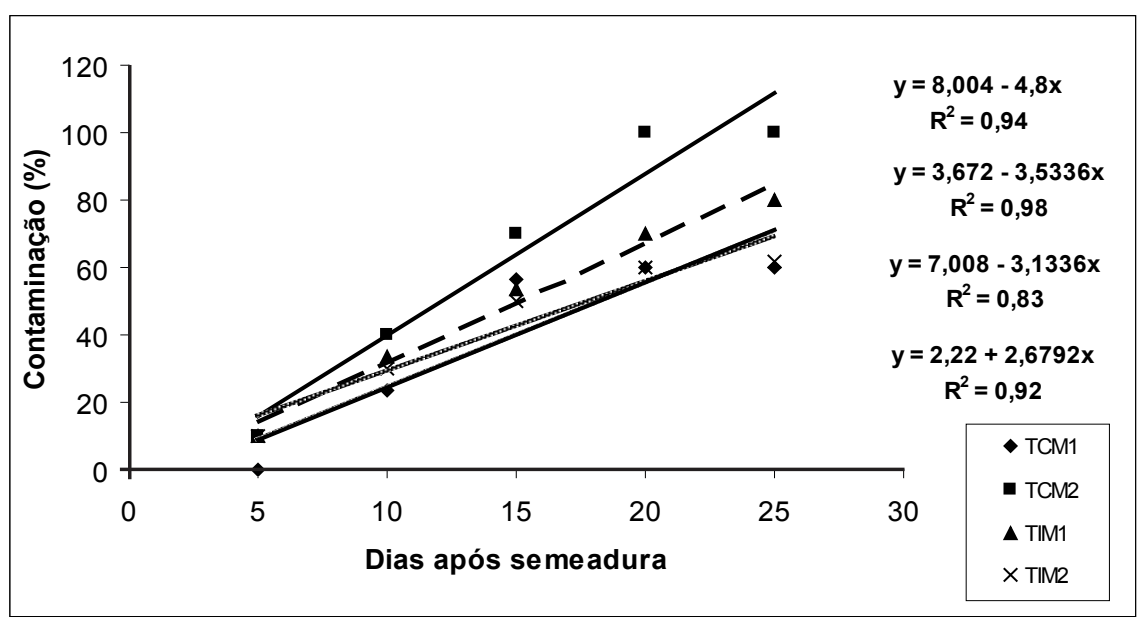

Figura 2. Contaminação de sementes de alcachofra cv. Nobre em dois meios de cultura (M1=1/2 MS e M2=MS completo), com (TC - tegumento cortado) e sem (TI - tegumento intacto) o corte lateral do tegumento. (Contamination of artichoke cv. Nobre seeds in two culture media $(\mathrm{M} 1=1 / 2 \mathrm{MS}$ and $\mathrm{M} 2=$ complete $\mathrm{MS})$, with $(\mathrm{TC}=$ cut tegument $)$ and without (TI= intact tegument) lateral cut of tegument. Passo Fundo, FAMV/UPF, 2006. 
sem tegumento obtiveram maior porcentagem de germinação. Itaya et al. (2005), estudando a germinação in vitro de aquênios de Viguiera discolor (Asteraceae), obtiveram 80\% de germinação quando os envoltórios externos foram retirados das sementes. Lima et al. (2007) verificaram, na germinação in vitro de sementes de urucum (Bixa orellana L.), que a retirada do tegumento incrementou a porcentagem de germinação, apresentando-se como o melhor método para superar a dormência.

Não foi observado efeito do meio de cultura e do tratamento do tegumento sobre a contaminação, que foi baixa, de $16,7 \%$ após sete dias da semeadura.

Assim, pode-se concluir que a obtenção de plântulas sadias de alcachofra cv. Nobre, para utilização como fonte de explantes no cultivo in vitro, é viável a partir da germinação in vitro de sementes. Com base nos experimentos realizados, pode-se indicar, para a obtenção de satisfatória taxa de germinação (77,5\%), baixa porcentagem de contaminação $(16,7 \%)$ e, em curto espaço de tempo (sete dias), plântulas em condições de fornecer explantes para repicagem, a técnica de assepsia das sementes com álcool $70 \%$ por $30 \mathrm{~min}$, posterior imersão, por dez minutos, em solução de hipoclorito de sódio contendo $2 \%$ de cloro ativo, e retirada do tegumento. A semeadura pode ser realizada em meio de cultura MS completo ou com concentração de sais reduzida à metade, mantidas as sementes em câmara de crescimento no escuro.

\section{AGRADECIMENTOS}

Os autores agradecem à Capes pela bolsa de Mestrado concedida ao primeiro autor.

\section{REFERÊNCIAS}

ANDRADE MW; LUZ JMQ; LACERDA AS; MELO PRA. 2000. Micropropagação da aroeira (Myracrodruon urundeuva $\mathrm{Fr}$. Allemão). Ciência Agrotécnica 24: 174-180.

AUGUSTIN L; GRANDO MF; SUZIN M; PIVA M; DONIDA BT; FLOSS EL. 2006. Micropropagação de uma cultivar de alcachofra para uso industrial. In: CONGRESSO BRASILEIRO DE OLERICULTURA, 46. Resumos... Goiânia: SOB (CD-ROM).

BACH EE; CASTRO OL. 2004. Germinação de sementes de Cattleya sp. (Orchidaceae) em cultura de tecido visando produção de mudas. Arquivo Instituto Biológico 71: 741-749.

BARBAM; DI LERNIA G; BABES G; CITRULLI F. 2004. Produzione e conservazione di germoplasma di carciofo di tipo romanesco esente da virus. Italus Hortus 11: 5-10.

BARBOSA W; DALL'ORTO FAC; OJIMA M. 1985. Cultura de embriões in vitro para o melhoramento de pessegueiros precoces. Bragantia 44: 465-472.

BASNIZKI Y; ZOHARY D. 1987. A seed-planted cultivar of globe artichoke. HortScience 22: 678-679.

BEWLEY JD; BLACK M. 1994. Seeds: physiology of development an germination. New York: Plenum. 445p.

BIZZETTO D; HOMECHIN M. 1999. Microrganismos associados a sementes de soja submetidas ao armazenamento, à assepsia e à retirada de tegumento. Ciência Agrotécnica 23: $130-139$

CADINU M; REPETTO A; FRAU A. 2003. Metodi di propagazione innovativi: la micropropagazione. In: Giornate nazionali di Studio Sul Carciofo: Vivaismo e Strategie di Sviluppo del Carciofo. Atti... Samassi: Ersat/ Cras/Ministerio delle Politeche Agricole e Forestali. p.17-21.

CAMARGO LS. 1992. As hortaliças e seu cultivo. Campinas: Fundação Cargill. 252p.

CASTRO LO; BACH EE. 2007. Germinação de sementes de Dendrobium sp. (Orchidaceae) e cultura de tecido visando produção de mudas. REUNIÃO ANUAL DO INSTITUTO BIOLÓGICO, 19. Resumos...São Paulo: RAIB. p.114.

CASTRO LO; COSTA JF; RODRIGUES CCD. 2007. Germinação de sementes de Vriesea simplex (Bromeliaceae) in vitro, visando a produção de mudas. In: REUNIÃO ANUAL DO INSTITUTO BIOLÓGICO, 19. Resumos... São Paulo: RAIB. p.115.

CHAVES AC; SCHUCH, MW; ERIG AC. 2005. Estabelecimento e multiplicação in vitro de Physalis peruviana L. Ciência Agrotecnica 29: 1281-1287.

COTREL. 2005. Programa de cultivo da alcachofra. Erechim: Departamento Técnico - Cooperativa Tritícola de Erechim. 12p.

CURSINO-SANTOS, JR; DEFINA, TPA.; MARTINEZ-ROSSI, NM. 2003. Os segredos das plantas e de seus patógenos na era molecular. Ribeirão Preto: RiMa, Sociedade Brasileira de Genética. 41 p.

CUSTÓDIO CC; MACHADO-NETO NB; CASEIRO RF; IKEDA M; BOMFIM DC. 2002. Germinação de sementes de urucum (Bixa ollerana L.). Revista Brasileira de Sementes 24: 197-202.

DOMINI LP; FERREIRA-MOURA I; GUISSO AP; SOUZA JA; VIÉGAS J. 2005. Preparo de lâminas foliares de aráceas ornamentais: desinfestação com diferentes concentrações de hipoclorito de sódio. Actq. Inst. Biol. 72 : 517-522.

DONIDA BT. 2004. Produção e qualidade de sementes da alcachofra. Pelotas: UFPEL. 54p (Tese doutorado).
EICH J; BAIER C; GRUN M; WAGENBRETH D; ZIMMERMANN R. 2005. Artichoke leaves used for herbal drug production: Influence of nitrogen fertilization on yield and on pharmaceutical quality. Acta Horticulturae 681: 545-551.

FRANCO ETH; FERREIRA AG. 2002. Tratamentos pré-germinativos em sementes de Didymopanax morototoni (Aubl.) Dcne. et Planch. Ciência Florestal 12: 1-10.

GRATTAPAGLIA D; MACHADO MA. 1998. Micropropagação. In: TORRES AC; CALDAS LS; BUSO JA (eds). Cultura de tecidos e transformação genética de plantas. Brasília: Embrapa Informação Tecnológica/Embrapa Hortaliças. p.183-260.

ISECHI K; PAIVA LC; MALUF WR. 1998. Como plantar alcachofra. Lavras: UFLA. 8 p. (Boletim Técnico de Hortaliças, 11).

ITAYA NM; VAZ APA; KERBAUY GB; FIGUEIREDO-RIBEIRO RCL. 2005. Produção de frutanos em calos e plântulas clonadas in vitro de Viguiera discolor Baker (Asteraceae). Acta Botânica Brasilica 19: 579-586.

LIMA RV; LOPES JC; SCHMILDT ER; MAIA AR. 2007. Germinação in vitro de urucum. Revista Brasileira de Sementes 29: 171-177.

MAUROMICALE G. 1984. La coltivazione del carciofo in Sicília. In: LA COLTIVAZIONE DEL CARCIOFO IN TOSCANA. Atti... Venturina: ETS. p.35-69.

MONIZ E. 2006. Influência de fatores ambientais no crescimento microbiano. Cooperativa de Ensino Superior - CRL/Instituto Superior de Ciências da Saúde - Sul/Escola Superior de Ciências da Saúde Egas Moniz, Caparica. Disponível em: http://www.egasmoniz.edu. pt/ficheiros/alunos/microbiologia/teorica/ Datashows-2006. Acessado em 12 de junho de 2007.

MURASHIGE T; SKOOG F. 1962. A revised medium for rapid growth and bioassays with tobacco tissue cultures. Physiologia Plantarum 15: 473-497.

NARVÁEZ E. 2002. Em el cultivo de alcahofa: la germinación de tecnologia das sus frutos. Cultivos Controlados 4: 20-22.

NOLETOLG; RIBEIRO MF; SILVEIRACE. 2003. Germinação in vitro de sementes de Jacaranda ulei Bureau e K. Schum (Bignoniaceae). In: CONGRESSO NACIONAL DE BOTÂNICA, 54. Resumos... Belém: SNB. (CD ROM).

PINHEIRO CSR; MEDEIROS DN; MACEDO CEC; ALLOUFA DAI. 2001. Germinação in vitro de mangabeira (Hancornia speciosa Gomez) em diferentes meios de cultura. Revista Brasileira de Fruticultura 23: 413416.

RESENDE MLV; SALGADO SML; CHAVES ZM. 2003. Espécies ativas de oxigênio na resposta de defesa de plantas a patógenos. Fitopatologia Brasileira 28: 123-130.

ROBLES RF. 2001. La alcachofra: nueva alternativa para la agricultura peruana. Lima: Prompex. 42p.

SUZIN M. Microrganismos e sua relação com plantas. 2004. Passo Fundo: UPF - Instituto de Ciências Biológicas. 68p. (Monografia especialização). 